\title{
Physically-based modeling of topographic effects on spatial evapotranspiration and soil moisture patterns through radiation and wind
}

\author{
M. Liu ${ }^{1,2}$, A. Bárdossy ${ }^{3}$, J. Li $^{4}$, and Y. Jiang ${ }^{1}$ \\ ${ }^{1}$ State Key Laboratory of Earth Surface Processes and Resource Ecology, Beijing Normal University, Beijing, China \\ ${ }^{2}$ Helmholtz Research Centre for Environment, Magdeburg, Germany \\ ${ }^{3}$ Institute of Modelling Hydraulic and Environmental Systems, University Stuttgart, Stuttgart, Germany \\ ${ }^{4}$ School of Civil, Environmental and Mining Engineering, the University of Adelaide, Adelaide, Australia \\ Correspondence to: M. Liu (min.liu@gmx.net)
}

Received: 23 June 2011 - Published in Hydrol. Earth Syst. Sci. Discuss.: 20 July 2011

Revised: 17 December 2011 - Accepted: 23 January 2012 - Published: 6 February 2012

\begin{abstract}
In this paper, simulations with the Soil Water Atmosphere Plant (SWAP) model are performed to quantify the spatial variability of both potential and actual evapotranspiration (ET), and soil moisture content (SMC) caused by topography-induced spatial wind and radiation differences. To obtain the spatially distributed ET/SMC patterns, the field scale SWAP model is applied in a distributed way for both pointwise and catchment wide simulations. An adapted radiation model from r.sun and the physically-based meso-scale wind model METRAS PC are applied to obtain the spatial radiation and wind patterns respectively, which show significant spatial variation and correlation with aspect and elevation respectively. Such topographic dependences and spatial variations further propagate to ET/SMC. A strong spatial, seasonal-dependent, scale-relevant intra-catchment variability in daily/annual ET and less variability in SMC can be observed from the numerical experiments. The study concludes that topography has a significant effect on ET/SMC in the humid region where ET is a energy limited rather than water availability limited process. It affects the spatial runoff generation through spatial radiation and wind, therefore should be applied to inform hydrological model development. In addition, the methodology used in the study can serve as a general method for physically-based ET estimation for data sparse regions.
\end{abstract}

\section{Introduction}

Evapotranspiration (ET) is a very important element in hydrological cycle, and it is adopted as the criteria for climate classification (Thornthwaite and Mather, 1955). Globally ET amounts to more than $60 \%$ of the precipitation that falls on the continents (Dingman, 2002), and in arid and semi-arid regions, it is much higher. At long-term, ET determines the regional water balance and hydro-ecological system, whereas at short-term, it affects the crop growth and yield, as well as the antecedent moisture conditions (AMC) which controls the rainfall-runoff generation processes, thus the hydrological response of the catchment. For most climate conditions, soil moisture content (SMC) and ET are strongly coupled together, and they are the key variables for soil water budget, which helps to optimize water balance management or forecast flash floods (Cassardo et al., 2002; Norbiato et al., 2008). Temporal ET and SMC dynamics also has a strong implication on the interpretation of global climate change.

ET/SMC show high spatial heterogeneity at different scales (Bresnahan and Miller, 1997; Western et al., 2002), resulted from the vertical and/or lateral water transfer which are subjected to the interaction of local atmospheric factors (precipitation, radiation, temperature, humidity, pressure, etc.), soil characteristics and vegetation covers. Many studies (e.g. Yeh and Eltahir, 1998; Quinn and Beven, 1993; 
Crave, 1997, etc.) suggest that lateral water redistribution in unsaturated and saturated zone is the major driving force for spatial soil moisture distribution. Lateral soil-water flow is independent from the ET process and can be described with the approach based on topographic index (Beven and Kirkby, 1979). However, Western et al. (1999) have found that lateral water redistribution is dominant only under wet conditions, while under dry conditions radiation which drives the vertical water transfer is more crucial. In the vertical direction, SMC is strongly coupled with ET, with the spatial patterns of both being subjected to spatial soil, vegetation and meteorological variabilities (El Maayar and Chen, 2006; Mohanty and Skaggs, 2001), which are to certain extent, related to topography. Jenny (1941) has given the well-known factors of soil formation, including climate, biota, topography and parent material and time, which has been validated by numerous case studies (Florinsky et al., 2002; Odeh et al., 1994). Studies have also confirmed the dependence of vegetation pattern on topography, climate and soil (Ostendorf and Reynolds, 1998; Schröder, 2006; Reed et al., 2009). However, pedogenesis and land cover evolution are both long-term processes and exhibit hight degree of randomness. Given that topography is a readily-available information, it is of great interest to quantify the spatial variability of ET/SMC that stems from topography. Sensitivity test for ET under the Mediterranean climate conditions by Bois et al. (2008) suggest that wind speed and solar radiation are the two most influential factors for reference ET. In this paper, we revisit the issue of spatial ET/SMC variability caused by the topographically related factors acting in the vertical direction, but focus on the two shot-term and more deterministic factors, i.e. radiation and wind. In addition to the usually investigated potential or reference ET, more efforts are shed to actual ET (ETA). Here the difference among the three widely used terms, potential ETP, actual ET and reference ET, has to be clarified. ETP is originally defined as "the amount of water transpired in a given time by a short green crop, completely shading the ground, of uniform height and with adequate water status in the soil profile" by Penman (1948), and it has been generalized to describe the maximum ET possible under specific climatic conditions with unlimited water availability in the soil for any vegetation. ETA is the exact water loss by soil and vegetation under water stress conditions. Reference ET is the definition adopted by FAO (1990), which refers to "the rate of evapotranspiration from a hypothetical reference crop with an assumed crop height of $0.12 \mathrm{~m}$, a fixed surface resistance of $70 \mathrm{~s} \mathrm{~m}^{-1}$ and an albedo of 0.23 , closely resembling the evapotranspiration from an extensive surface of green grass of uniform height, actively growing, well-watered and completely shading the ground". In this work, the term ETP in general sense and the term ETA are adopted.

In contrast to other hydrological parameters such as precipitation and temperature, reliable direct measurement of ET/SMC is more difficult and expensive. Moreover, the strong spatial variation of ET/SMC to the local meteorological and hydrological conditions, referred by Western et al. (2002) as scale effect, together with the high cost of measurements, render all types of point measurements impractical for spatial mapping. Remote sensing are nowadays widely deployed to measure SMC and to derive ET. However, limitations due to the interfering signal of soil surface roughness and vegetation canopy and the restricting signal penetration depth prevent the operational application of soil moisture remote sensing at current stage (Western et al., 2002). Alternatively, inferring ET/SMC with modeling approach using other remotely sensed parameters, such as land surface temperature (LST), vegetation index (NDVI/EVI), etc. are widely explored (Cleugh et al., 2007; Wang et al., 2007; Mu et al., 2007). Most methods are targeting ETP evaluation. Empirical equations based on simple meteorological input(s) is one of the most commonly used approach for the estimation of regional ET. Xu and Singh (2000) provided an extensive review of the temperature and radiation based method. Some empirical methods have been developed to utilize the remotely sensed LST and vegetation index data to calculate ETA, such as triangle method (Price, 1990), B-method (Carlson et al., 1995), temperature/vegetation dryness index (TVDI) (Andersen et al., 2002). A good overview of the remote-sensing based techniques can be found in Verstraeten et al. (2008).

More physically sound approaches are based on the conservation of either energy, mass or both. Penman-Monteith method, also called the combination method, because it eliminates the surface temperature and does not need an explicit calculation of sensible heat flux, is the most popular approach used in modeling the physical process of ET. The surface energy balance method, usually applied in some land surface models (LSM), on the contrary, try to employ remotely sensed LST data to derive aerodynamic surface temperature and to explicitly determine sensible heat flux, so that the latent heat flux associated with ET can be calculated as a residual (Bastiaanssen et al., 1998; Su, 2002). Jensen et al. (1990) analyzed the performance of 20 different ET formulas against lysimeter data for 11 stations around the world under different climatic conditions, and the PenmanMonteith approach is ranked as the best for all climatic conditions. This paper will apply the the Soil Water Atmosphere Plant (SWAP) model, which contains the Penman-Monteith approach as the core module for ET estimation, to avoid the complexity of surface temperature estimation associated typically with LSMs.

A set of numerical experiments with the SWAP model are designed to investigate the spatial ET/SMC variability originating from spatial wind and radiation difference. First, the studying area and the available data, from both station observation and remote sensing, will be presented. Solar radiation and mesoscale wind models generating the spatial radiation and wind patterns will be introduced briefly. Then an overview of the SWAP model will be given, followed by the presentation of boundary conditions and the design of 
the numerical experiments. Both pointwise and spatial simulations are performed. The pointwise experiment examines the effect of soil on ET/SMC variability in addition to the effects of solar radiation and wind. The effects of radiation, wind and their interaction are tested in three numerical experiments by different combinations of inputs. The experiment with actual land use (LU) is to approximate the topographic induced ET/SMC variability under the most realistic conditions. The results are presented statistically followed by a discussion.

\section{Study area and data}

\subsection{Study area}

The study is focusing on the topographic effects on ET/SMC, specifically water exchange and transfer in the vertical direction, while neglecting the horizontal/lateral water redistribution. For such purpose, a delineated water basin is not necessary. Instead, a region with rich topographic features, i.e. an area with so-called complex terrain, is required to reflect a wide range of topographic effects. In this paper, a $93 \times 76 \mathrm{~km}^{2}$ rectangular region containing both mountainous area and flood plain in the state Baden-Wuerttemberg, southern Germany is taken as the study area (see the outer domain in Fig. 1). A smaller area of $20 \times 20 \mathrm{~km}^{2}$ in the northeast (the inner domain) is studied in comparison to the outer domain to investigate the scale effects. The outer domain and the inner domain are simulated at $1000 \mathrm{~m}$ and $100 \mathrm{~m}$ resolution respectively. The Black Forest on the western border of the study area consists of crystalline bedrock whereas karstic limestone is frequently found in the eastern part of the study area. Both hill chains are characterized by steeper slopes and soils with low storage capacity. The river valleys and plains in the northern part mostly consist of thick, fertile soils. The climate can be characterized as temperate humid, with a long-term average annual precipitation of $950 \mathrm{~mm}$ for the state, varying from $700 \mathrm{~mm}$ to $1680 \mathrm{~mm}$, with higher precipitation in the mountainous regions and lower in the flat areas.

\subsection{Meteorological data}

For the numerical experiments in this study, the year 2002 with a mean annual precipitation of $970 \mathrm{~mm}$ for the state and $1100 \mathrm{~mm}$ for the study region which can be considered as the average climate conditions, is taken. Daily precipitation and temperature data are obtained at the station Rottenburg-Kiebingen from German Weather Service (DWD). Both daily maximum, minimum and mean temperature are available. As the station does not provide humidity data, it is obtained from the nearest meteorological station Stuttgart. Humidity can also be estimated from temperature data with empirical formulas as shown by Thornton et al. (1997). Station radiation and wind data are also available at

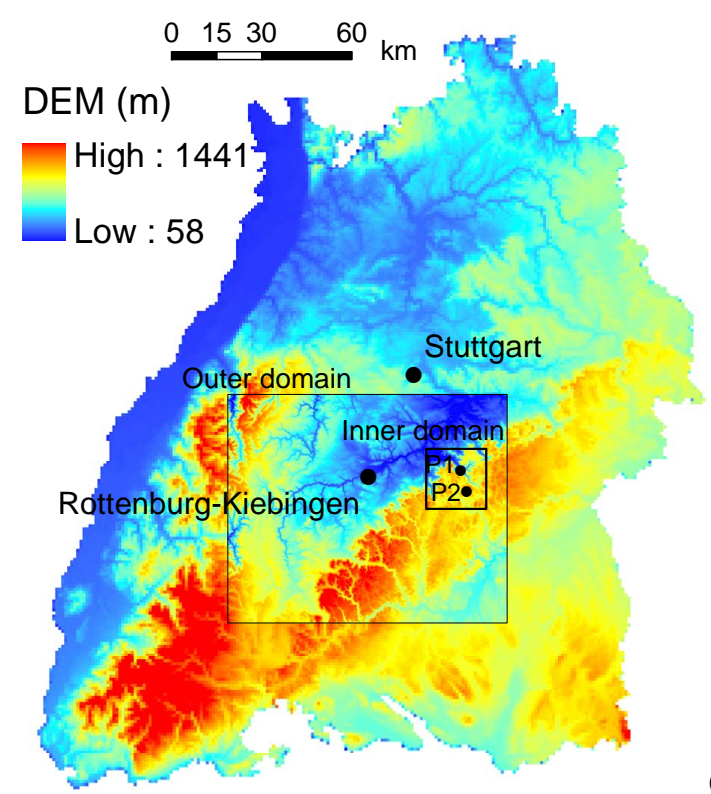

(a)

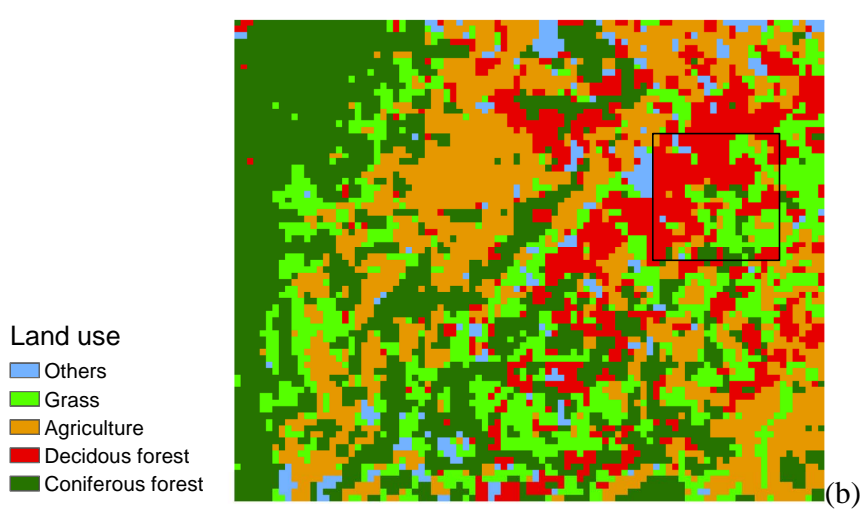

Fig. 1. Study area and reclassified land cover in the study area. (a) Study area and (b) land use in the study area.

the station Stuttgart for the period from 2002 to 2007, which are used to calibrate the radiation and wind models.

\subsection{Land use and LAI}

Land use data (Landsat 1993) of the study area is reclassified into 5 classes (grass, agriculture, deciduous forest, coniferous forest and bare soil) by merging the similar land use types to simplify the parameterization of ET modeling. Leave Area Index (LAI) required by the SWAP model are obtained from MODIS 8-day composite data (Yang et al., 2006). A preliminary investigation of the MODIS LAI data shows that the cell-based LAI values exhibit a strong fluctuation which may come from the data uncertainty. Figure 2a shows LAI of two randomly selected points with the same vegetation cover, in this case, grass. To reduce such point variability, instead of a point specific LAI value, the mean LAI of a given land use is applied. Figure $2 \mathrm{~b}$ shows the land use specific LAI, which gives a clear discrimination of each LU type. 

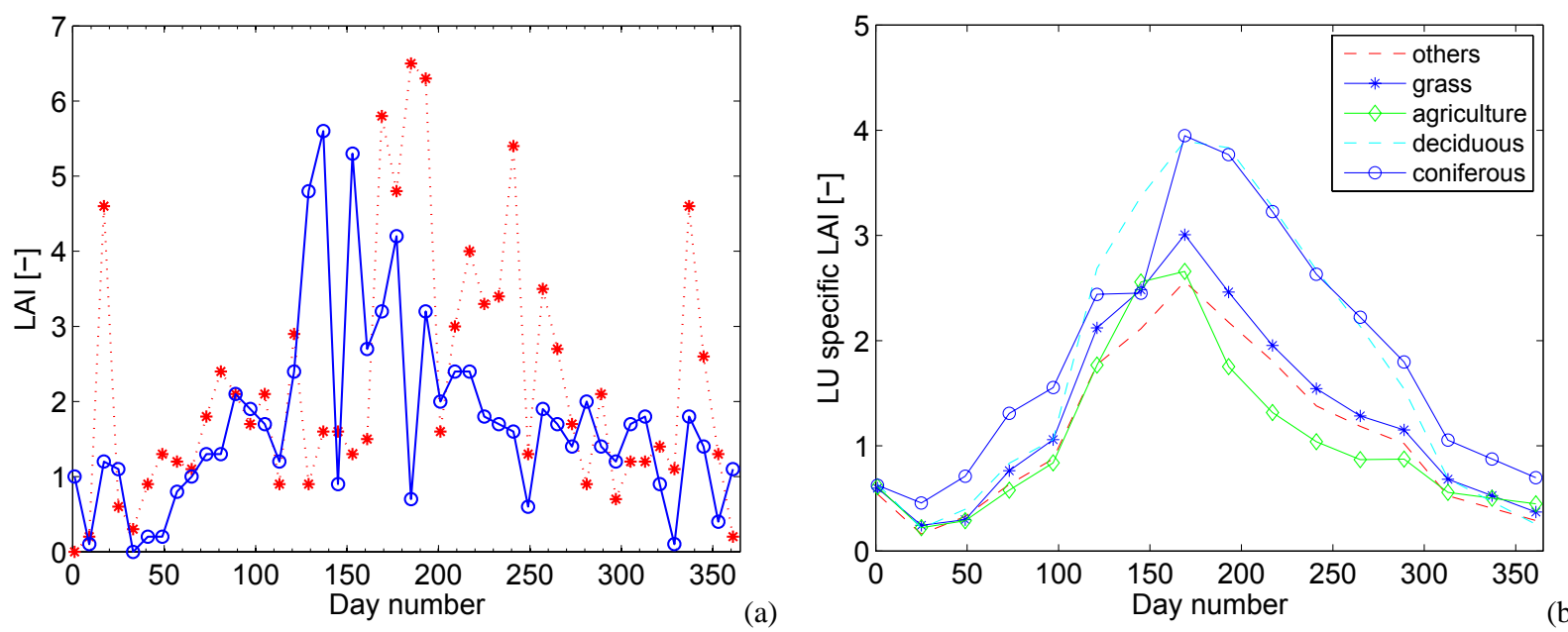

Fig. 2. Cell-based LAI at two randomly selected points with grass cover (a) and land use specific LAI for 5 different vegetation covers (b).

\section{Models}

To reflect the spatial ET/SMC variability, the first step is to model the spatial radiation and wind patterns. In this research, an adapted r.sun model and the mesoscale METRAS PC model are applied to simulate the daily radiation and wind patterns respectively. These patterns are used then to drive the SWAP model to obtained ET/SMC fields.

\subsection{Radiation model r.sun}

The original r.sun model is a module for modeling of direct, diffuse and reflected shortwave radiation based on topographic properties in the GRASS open GIS software (Hofierka and Suri, 2002). The model can not only reflect geometrical solar-earth-surface relationship for calculating the extraterrestrial radiation, but also considers the atmospheric attenuation to obtain potential radiation under clear-sky conditions. It can also account for cloud overcast to estimate the actual radiation, if cloud parameters such as the clear-sky index (Kasten, 1983) can be provided to the model. Liu et al. (2011) have adapted the r.sun model to a stand-along program implemented together with the remote-sensing based Heliosat-2 Rigollier et al. (2004) approach to parameterize cloud. The Heliosat-2 method applies the albedo data derived from the satellite, i.e. Meteosat VIS (visible spectrum range from 0.5 to $0.9 \mu \mathrm{m}$ ) band images to estimate the clear-sky index (Cano et al., 1986; Rigollier et al., 2004). The model has been tested for three stations in Baden-Wuerttemberg and achieved an average $R^{2}$ above 0.9 . In this paper, daily actual radiation patterns are obtained with the adapted $r$.sun model.

\subsection{Wind model METRAS PC}

METRAS PC is the PC version of the MEsoscale TRAnsport and fluid (Stream) Model (METRAS) (Schlünzen et al., 2001), which is a three dimensional, non-hydrostatic wind model to downscale from the geostrophic wind to local wind field. The model is capable of simulating wind, temperature, humidity, cloud- and rain-water-content, as well as pollutant concentration field over areas up to $800 \times 800 \mathrm{~km}^{2}$ with high accuracy for wind field. It applies a horizontally non-uniform but orthogonal grid and vertically a non-orthogonal terrainfollowing coordinate system. The model can reflects the topographic and land use modification of wind, e.g. sheltering, amplification due to wind tunnel effects etc. It is proven to be an "up-to-date" mesoscale model with complete functionalities for flow and transport simulation, and its capability in modeling mesoscale wind fields has been validated by numerous case studies (e.g. Wu and Schlünzen, 1992; Lenz et al., 2000; Schueler and Schlünzen, 2006). Moreover, because the model fulfills the requirements of VDI (2005) which requires a hit rate higher than $66 \%$ compared with observed data for tunnel simulation and $95 \%$ compared to analytical solution, it is widely adopted in practical applications, such as air pollution prediction. In addition, the model has also been tested by World Meteorological Organization (WMO, Baklanov et al., 2008; Mikhail Sofiev and Miranda, 2009). In this study, the input geostrophic wind data for the study area is retrieved from NCEP/NCAR Reanalysis I data (Kalnay and Coauthors, 1996). The data is avlaiable daily for 17 pressure levels $(1000 \sim 10$ mbar, some data, such as humidity, has less data levels). Following Frank and Landberg (1997), the wind data at 850 mbar level for the year 2002 are chosen at the grid point $\left(10.0^{\circ} \mathrm{E}, 50.0^{\circ} \mathrm{N}\right)$ as the synoptic inputs.

\subsection{The SWAP model}

The SWAP model is an agro-hydrological model that simulates transport of water, solutes and heat in saturated/unsaturated soils (van Dam et al., 1997). SWAP is designed ideally for field scale study, but it can also be applied 
to regional scale. It considers a one-dimensional column in the vertical direction, with the lower atmospheric layer being the upper boundary for the model and the unsaturated zone or the upper part of the saturated zone being the bottom boundary. The bottom boundary conditions can be Dirichlet, Neumann, Cauchy or some mixed type. The soil water flow is simulated by the Richard's Equation (Eq. 1) discretized in a implicit finite difference scheme.

$\frac{\delta \theta}{\delta t}=\frac{\delta}{\delta z}\left[K(h)\left(\frac{\delta h}{\delta z}+1\right)\right]+S(h)$

where $t$ denotes time [d], $z$ is the vertical coordinate taken as positive upwards [cm], $K(h)$ is the hydraulic conductivity $\left[\mathrm{cm} \mathrm{d}^{-1}\right]$ described by the Van Genuchten-Mualem model and $S(h)$ is a sink term standing for the water extraction by plant roots $\left[\mathrm{cm}^{3} \mathrm{~cm}^{-3} \mathrm{~d}^{-1}\right]$, i.e. actual transpiration (TA).

The actual transpiration is the integrated root water uptake of each root layer taking into account the reduction due to water and/or salinity stress (see Eq. 4). In absence of any stress, the total root uptake capacity equals to the potential transpiration rate.

$$
\operatorname{RX}_{\mathrm{p}}(z)=\frac{l_{\text {root }}(z)}{\int_{-D_{\text {root }}}^{0} l_{\text {root }}(z) \mathrm{d} z} \mathrm{TP}
$$

$\operatorname{RX}_{\mathrm{a}}(z)=\alpha_{\mathrm{r}} \mathrm{RX}_{\mathrm{p}}(z)$

$\mathrm{TA}=\int_{-D_{\text {root }}}^{0} \mathrm{RX}_{\mathrm{a}}(z) \mathrm{d} z$

where $l_{\text {root }}(z)$ is the root density $\left[\mathrm{cm}^{3} \mathrm{~cm}^{-3}\right]$ and $\operatorname{RX}_{\mathrm{p}}(z)$ and $\mathrm{RX}_{\mathrm{a}}(z)$ are the potential and actual root water extraction rate $\left[\mathrm{cm} \mathrm{d}^{-1}\right]$ at depth $z$ respectively. TP is the potential transpiration rate $\left[\mathrm{cm} \mathrm{d}^{-1}\right] . D_{\text {root }}$ is the root layer thickness [cm], $\alpha_{\mathrm{r}}$ is the reduction factors due to water, salinity stress and frozen conditions (dimensionless). Figure 3 shows the water stress coefficient $\alpha_{\mathrm{rw}}$ as a function of soil water pressure head. In the range $h_{3}<h<h_{2}$ root water uptake is optimal. Below $h_{3}$ root water uptake linearly declines until zero at $h_{4}$ (permanent wilting point). The threshold pressure $h_{3}$ increases with potential transpiration rates. For low potential transpiration $\mathrm{TP}_{\text {low }}$, the threshold pressure $h_{31}$ is lower than the threshold pressure $h_{3 \mathrm{~h}}$ at high potential transpiration rate $\mathrm{TP}_{\text {high. }}$. Above $h_{2}$ root water uptake linearly decreases due to insufficient aeration until zero at $h_{1}$.

Including TP, three potential rates are modeled by the Penman-Monteith algorithm (Eq. 5) in SWAP: potential ET of wet crop $\left(\mathrm{ETP}_{\mathrm{w}}\right)$, potential ET of dry crop $\left(\mathrm{ETP}_{\mathrm{d}}\right)$, and potential evaporation of bare soil $\left(\mathrm{EP}_{\mathrm{S}}\right)$, based on which the actual rates of a fully covered or non-covered surface can be calculated.

$\operatorname{ETP}_{\mathrm{d}}=\frac{\Delta_{\mathrm{v}}\left(G_{\mathrm{n}}+L_{\mathrm{n}}\right)+\rho_{\mathrm{a}} c_{\mathrm{a}} C_{\mathrm{at}}\left(e_{\mathrm{s}}-e_{\mathrm{a}}\right)}{\rho_{\mathrm{w}} \lambda_{\mathrm{v}}\left(\Delta_{\mathrm{v}}+\gamma_{\mathrm{pc}}\left(1+C_{\mathrm{at}} / C_{\mathrm{can}}\right)\right)}$

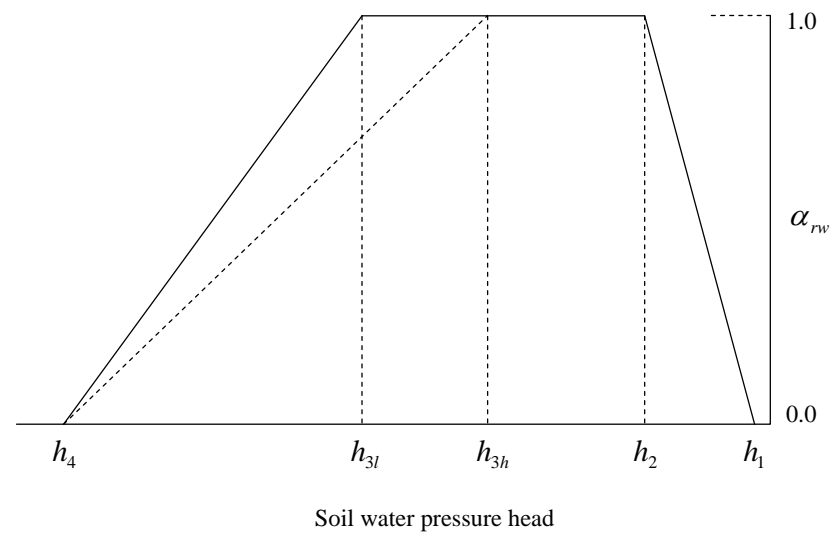

Fig. 3. Reduction coefficient for root water uptake.

with

$\mathrm{ET}=$ evapotranspiration rate $\left[\mathrm{LT}^{-1}\right]$

$\Delta_{\mathrm{V}}=$ slope of the vapor pressure curve $\left[\mathrm{ML}^{-1} \mathrm{~T}^{-3}\right]$

$G_{\mathrm{n}}=$ net shortwave radiation $\left[\mathrm{EL}^{-2} \mathrm{~T}^{-1}\right.$ ]

$L_{\mathrm{n}}=$ net longwave radiation $\left[\mathrm{EL}^{-2} \mathrm{~T}^{-1}\right]$

$\rho_{\mathrm{a}}=$ air density $\left[\mathrm{ML}^{-3}\right]$

$c_{\mathrm{a}}=$ heat capacity of air $\left[\mathrm{EM}^{-2} \mathrm{~T}^{-1}\right]$

$e_{\mathrm{S}}=$ the saturation vapor pressure $\left[\mathrm{ML}^{-1} \mathrm{~T}^{-2}\right]$

$e_{\mathrm{a}}=$ actual vapor pressure $\left[\mathrm{ML}^{-1} \mathrm{~T}^{-2}\right]$

$\rho_{\mathrm{w}}=$ water density $\left[\mathrm{ML}^{-3}\right]$

$\lambda_{\mathrm{V}}=$ latent heat of vaporization $\left[\mathrm{EL}^{-2} \mathrm{~T}^{-1}\right.$ ]

$\gamma_{\mathrm{pc}}=$ psychrometric constant $\left[\mathrm{ML}^{-1} \mathrm{~T}^{-3}\right]$

$C_{\mathrm{at}}=$ atmospheric conductance $\left[\mathrm{LT}^{-1}\right]$

$C_{\text {can }}=$ canopy conductance $\left[\mathrm{LT}^{-1}\right.$ ]

The two terms in the numerator of Eq. (5) represents the two driving forces of ET: the radiation and the aerodynamic force (wind). By replacing $C_{\text {can }}$ with conductance of wet canopy and soil, $\mathrm{ETP}_{\mathrm{w}}$ and $\mathrm{EP}_{\mathrm{s}}$ can be calculated similarly. For partly covered soils, the potential ET of wet or dry crop is partitioned, following Eq. (6) into potential evaporation (EP) and potential transpiration (TP) which is reduced by soil cover fraction (SC) as shown in Eq. (7) or the energy interception by LAI of the vegetated area (see Eq. 8).

$\mathrm{TP}=\mathrm{ETP}_{\mathrm{d}}-\mathrm{EP}$
$\mathrm{EP}=(1-\mathrm{SC}) \mathrm{EP}_{\mathrm{s}}$
$\mathrm{EP}=\mathrm{EP}_{\mathrm{s}} e^{-\kappa_{\mathrm{gr}} \mathrm{LAI}}$.

Here, $\kappa_{\mathrm{gr}}$ is the extinction coefficient for solar radiation. In the SWAP model, the actual soil evaporation (EA) is determined by the minimum value of EP, the restricted Darcy flux $E_{\max }$ at the top soil layer (see Eq. 9) and/or the results from the empirical evaporation functions of Black et al. (1969) or Boesten and Stroosnijder (1986).

$E_{\max }=K_{1 / 2}(\theta)\left(\frac{h_{\mathrm{atm}}-h_{1}-z_{1}}{z_{1}}\right)$. 
Here, $K_{1 / 2}(\theta)$ [ $\mathrm{cm} \mathrm{d}^{-1}$ ] is the average hydraulic conductivity between the soil surface and the first node as a function of soil water saturation $\theta[-], h_{\mathrm{atm}}$ is the soil water pressure head $[\mathrm{cm}]$ in equilibrium with the air relative humidity, $h_{1}$ is the soil water pressure head of the first node, and $z_{1}$ is the soil depth $[\mathrm{cm}]$ at the first node.

The crop module of the SWAP model provides canopy condition intercepting precipitation and energy and the roots distribution function for plant uptake. The simple crop model adopted for this study prescribes crop development stage as a function of either LAI or soil cover fraction, along with crop height and rooting depth, independent of stress factors.

Infiltration excessive surface runoff $q_{\mathrm{s}}\left[\mathrm{cm} \mathrm{d}^{-1}\right]$ is simulated with a non-linear reservoir model (see Eq. 10).

$q_{\mathrm{s}}=\frac{1}{\gamma_{\text {sill }}}\left(h_{\text {pond }}-Z_{\text {sill }}\right)^{\beta_{\text {sill }}}$.

The excess water on the soil surface first builds up a ponded reservoir until the pond water level $h_{\text {pond }}$ [cm] exceeds a threshold ponding level $Z_{\text {sill }}[\mathrm{cm}] . \gamma_{\text {sill }}[\mathrm{d}]$ is the runoff resistance and $\beta_{\text {sill }}$ is an exponent for the reservoir model.

Discharge from groundwater to surface water system which may consist of up to five level drainage ditches, canals or streams is described with the following general formulation:

$q_{\mathrm{drain}, i}=\frac{\phi_{\mathrm{gwl}}-\phi_{\mathrm{drain}, i}}{\gamma_{\mathrm{drain}, i}}$

where $q_{\mathrm{drain}, i}$ [ $\mathrm{cm} \mathrm{d}^{-1}$ ] represents the drainage/infiltration to or from the $i$-th level (in this study 2 levels) of surface water system, and $\phi_{\mathrm{drain}, i}[\mathrm{~cm}]$ is the corresponding surface water level. $\phi_{\mathrm{gwl}}[\mathrm{cm}]$ is the groundwater level and $\gamma_{\mathrm{drain}, i}[\mathrm{~d}]$ is the drainage resistance.

\section{SWAP Model setup}

As the focus of this research is the spatial ET/SMC variability driven by the topographically derived forces in the vertical direction, the effects of lateral water redistribution will be intentionally excluded by simplifying the lateral flux in the vadose zone and of groundwater. As SWAP is a onedimensional, vertically directed model, it is best suited for this purpose. First, the model is applied to two representative plots (P1 and P2) with contrasting topographic features (see Fig. 1) to check the topographic effects by varying the radiation and wind inputs while keeping other factors identical. Effects of soil hydraulic properties are tested with two different soil configurations: a less permeable two-layer configuration of clay (soil A) on top of loam (soil B) which is typical for the region and a more permeable combination of soil $\mathrm{C}$ in the upper layer and soil D in the lower layer. For both cases, the upper layer is $30 \mathrm{~cm}$ thick with the lower layer extending to the aquitard.
To simulate the spatial ET/SMC, the SWAP model is adapted to a batch mode, running for each grid cell. Four types of spatial simulations applying different combinations of spatial and station data, referred to as numerical experiments because of the simplification of the soil-water regime and the application of some assumed data such as soil properties, are tested in this research to investigate the effect of radiation, wind, their interaction and land use respectively:

- Experiment 1: spatial actual radiation, station wind, homogeneous vegetation;

- Experiment 2: station radiation, spatial wind, homogeneous vegetation;

- Experiment 3: spatial actual radiation, spatial wind, homogeneous vegetation;

- Experiment 4: spatial actual radiation, spatial wind, actual land use.

All numerical experiments, including the pairwise comparison, are conducted at two different resolutions, $100 \times 100 \mathrm{~m}^{2}$ for the inner domain and $1 \times 1 \mathrm{~km}^{2}$ for the outer domain to check the scale effects. The boundary conditions of each cell are identical except the groundwater level. A simplification of regional groundwater table is assumed groundwater depth is linearly related to the local elevation, with a groundwater depth of $0.7 \mathrm{~m}$ at the lowest elevation close to the river and a depth of $1.5 \mathrm{~m}$ at the highest elevation. This is an approximation to the TOPMODEL concept, in which the groundwater level increases with the catching area (Beven et al., 1995). A shallow groundwater aquifer of $3 \mathrm{~m}$ on top of an impervious aquitard is assumed for the region, implying a zero bottom flux boundary. Infiltrated water from each cell reaching the groundwater table is discharged through the drainage system lying $5 \mathrm{~cm}$ below the groundwater table directly to nearest surface water bodies and no lateral flux between cells is considered. The tile drain is a common practice for the lowland arable land in the study area. For the highland area, such settings are essentially equivalent to the boundary settings of free drainage at the bottom to deep groundwater, which is compliance to the karstic geologic formation in most mountainous region of the study area.

The upper boundary of the SWAP model is governed by meteorological fluxes and root zone flux. Meteorological data, such as temperature, precipitation and humidity are station observations at Rottenburg-Kiebingen. Station radiation and wind data from Stuttgart station is used in case that spatially constant value is required for a given experiment.

The simple crop model of SWAT is adopted for the simulations. For homogeneous vegetation, natural grass is assumed and the parameters are assigned the recommended values from the SWAP manual. In the case of heterogeneous vegetation, land use specific LAI processed from MODIS is written in to a look-up table for different plant development 
Table 1. Crop specific parameters for SWAP modeling.

\begin{tabular}{lrrrccc}
\hline & & \multicolumn{5}{c}{ characteristic suction heads [cm] } \\
\cline { 3 - 7 } & $D_{\text {root }}[\mathrm{cm}]$ & $h_{1}$ & $h_{2}$ & $h_{3 \mathrm{~h}}$ & $h_{31}$ & \multicolumn{1}{c}{$h_{4}$} \\
\hline Natural grass & 60 & 0.0 & -1.0 & -200.0 & -800.0 & -8000.0 \\
Maize & $5 \sim 100$ & -15.0 & -30.0 & -325.0 & -600.0 & -8000.0 \\
Pine forest & 70 & -0.0 & -1.0 & -600.0 & -600.0 & -6000.0 \\
Deciduous forest & 100 & -1.0 & -2.0 & -600.0 & -600.0 & -6000.0 \\
\hline
\end{tabular}
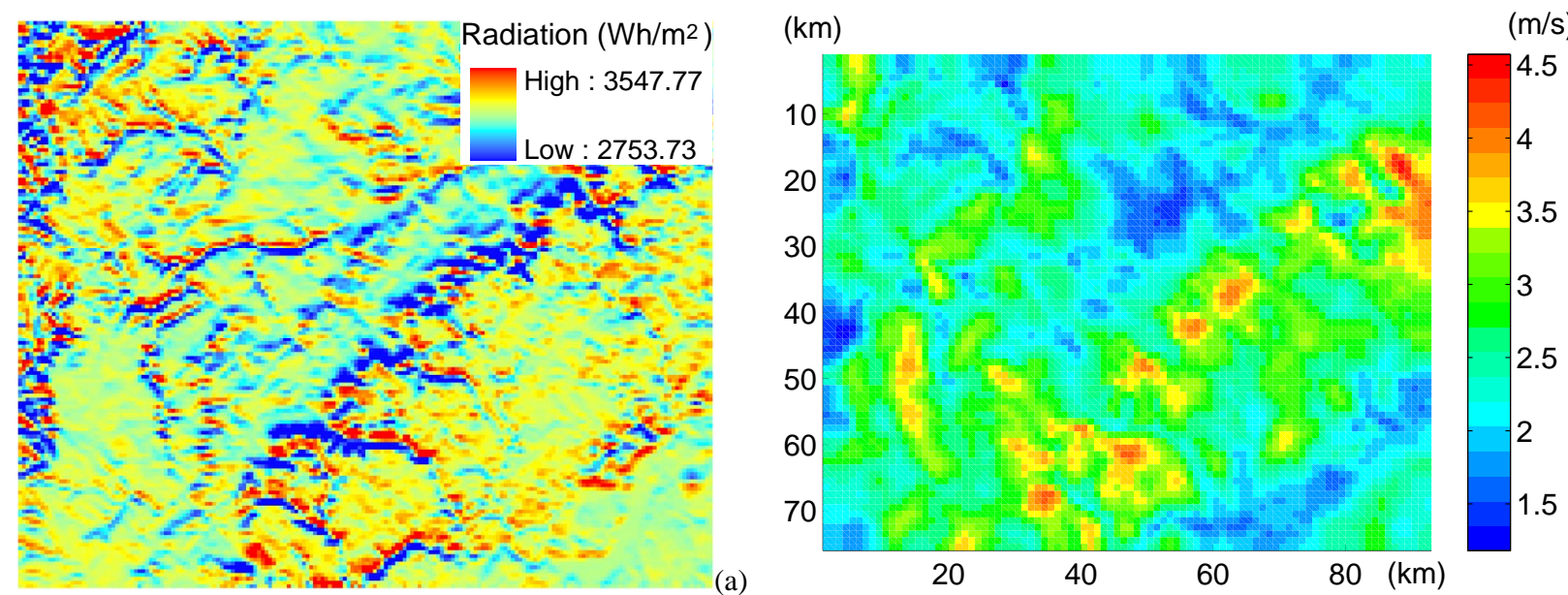

$(\mathrm{m} / \mathrm{s})$

Fig. 4. Mean daily actual radiation (a) and wind pattern (b) in the study area.

stages. The critical pressure values for root water uptake and root zone depths can be found in Table 1. Other parameters, when not specified are assigned the default values suggested by SWAP.

\section{Results}

\subsection{Spatial patterns of radiation and wind}

Daily radiation and wind speed patterns are generated with the adapted r.sun and METRAS PC model respectively. Table 2 shows the correlation between the simulated patterns of radiation and wind with three primary topographic parameters, i.e. elevation $(\delta)$, slope $(\beta)$ and aspect $(\gamma)$, for the outer domain. To be mentioned, correlation of radiation with aspect and slope are calculated to their functional values of sine and cosine respectively, given the known trignometrical relationship between radiation and topography. The dependence of wind on topographic is rather complicated, therefore the correlation coefficients are derived based on the original values. It shows that aspect has a remarkable impact on radiation, whereas the most significant topographic factor for wind speed is elevation, which can also be verified from the mean radiation and wind patterns (see Fig. 4). In general, the
Table 2. Correlation between radiation/wind patterns and topographic parameters for the outer domain $(\bar{\rho}$ is the yearly average of correlation coefficients between daily patterns and topographic parameters, and $\sigma$ is the corresponding standard deviation. $\tilde{\rho}$ is the correlation coefficients of mean daily pattern with topographic parameters.)

\begin{tabular}{lccrc}
\hline & & \multicolumn{3}{c}{ topographic parameters } \\
\cline { 3 - 5 } & & $-\cos \gamma$ & $\sin \beta$ & $\delta$ \\
\hline \multirow{4}{*}{ radiation } & $\bar{\rho}$ & 0.621 & -0.437 & 0.142 \\
& $\sigma$ & 0.170 & 0.245 & 0.127 \\
& $\tilde{\rho}$ & 0.739 & -0.262 & 0.176 \\
\hline \multirow{4}{*}{ wind } & & $\gamma$ & $\beta$ & $\delta$ \\
\cline { 2 - 5 } & $\bar{\rho}$ & 0.066 & 0.012 & 0.302 \\
& $\sigma$ & 0.007 & 0.011 & 0.066 \\
& $\tilde{\rho}$ & 0.127 & 0.057 & 0.594 \\
\hline
\end{tabular}

correlation coefficients of yearly mean daily radiation/wind pattern $(\tilde{\rho})$ are higher than the yearly mean of the daily correlation coefficients $(\bar{\rho})$. 

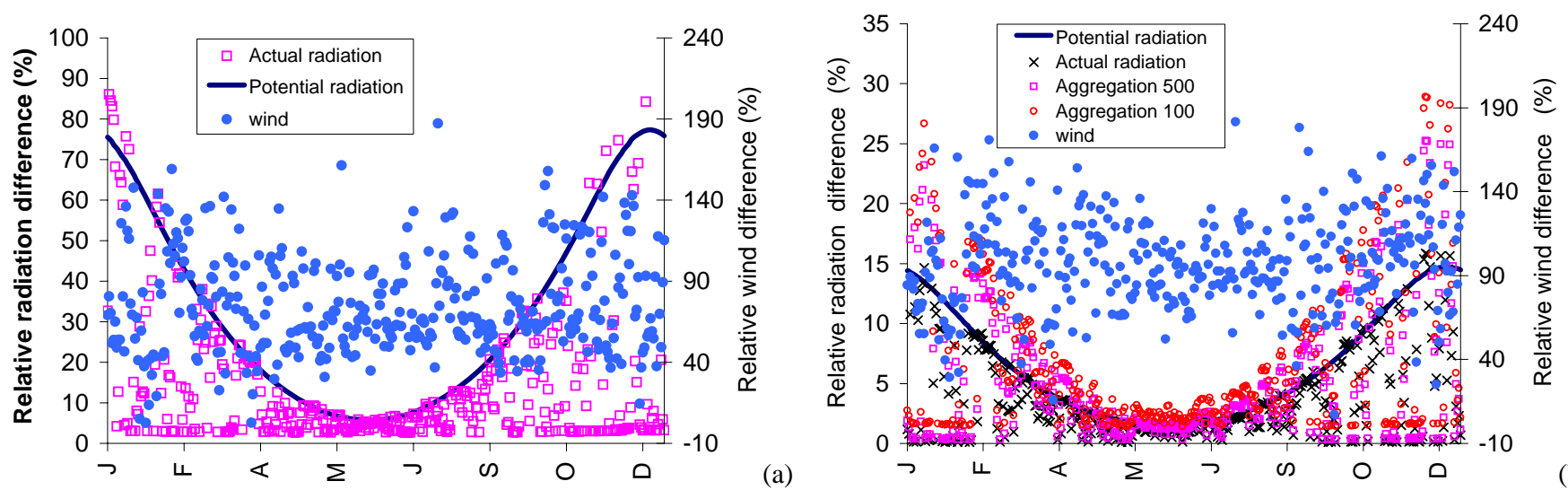

(b)

Fig. 5. Spatial variation of wind and radiation over time, (a) Inner domain and (b) outer domain.

Figure 5 shows the daily spatial variation of radiation and wind speed expressed in the interquantile range (NIQR), $\frac{P_{90}-P_{10}}{\mu_{\mathrm{s}}}$, over the year. The spatial variabilities of both solar and wind are found to be very stable in summer but vary strongly in winter. The wind fields of both the inner and outer domain are simulated at $1000 \mathrm{~m}$ resolution. For both domains, the difference between the lower and upper 10 quantile of wind force is around $80 \%$ of the area mean wind speed, but can be as twice higher for some days (NIQR $>2.0)$. For radiation, the inner domain is simulated at $100 \mathrm{~m}$ resolution whereas the outer domain is simulated at $1000 \mathrm{~m}$ resolution. In addition to actual radiation, the variability of potential radiation is also displayed in the figure shown in the solid line, which is in general higher than the variability of actual radiation except for very few winter days. It is obvious that the NIQR is much higher at fine scale simulation (up to $90 \%$ ) than at the coarse scale (up to $15 \%$ ). To compare the loss of spatial variability of solar radiation at coarse scale, aggregated radiation from fine resolution to coarse resolution is applied. Aggregations from both $100 \mathrm{~m}$ and $500 \mathrm{~m}$ to $1000 \mathrm{~m}$ have been tried. Given that the improvement by using $100 \mathrm{~m}$ is only marginal while the computational cost is 25 times more expensive, aggregation from $500 \mathrm{~m}$ is applied in this study. Table 3 shows the mean daily spatial variation over the year and for two different seasons, as well as the spatial variation of the mean daily radiation, both potential and actual, and of wind for both domains. Because finer resolution can better resolve the topographic diversity, it has caused stronger spatial variability for the inner domain than the outer domain in terms of radiation. However, the wind pattern of the outer domain shows higher variability than the inner domain, because both domains are simulated at the same resolution and the outer domain covers more diversified topographic features. The potential radiation exhibits a much higher variation than the actual radiation, so does the variation in winter than in summer. The seasonal variation of wind is more constant over the
Table 3. Spatial variability of wind and radiation (Summer gives the average of daily NIQR from May to August, and winter averages daily NIQR from November to February. mean is the average of daily NIQR of the whole year, and yearly is the NIQR of mean daily wind or radiation of the year.)

\begin{tabular}{llrrr}
\hline & & $\begin{array}{r}\text { Potential } \\
\text { radiation }\end{array}$ & $\begin{array}{r}\text { Actual } \\
\text { radiation }\end{array}$ & wind \\
\hline \multirow{5}{*}{ Inner domain } & summer & $8.96 \%$ & $5.8 \%$ & $73.2 \%$ \\
& winter & $57.5 \%$ & $26.9 \%$ & $82.0 \%$ \\
& mean & $32.8 \%$ & $14.1 \%$ & $75.8 \%$ \\
& yearly & $21.2 \%$ & $13.0 \%$ & $37.0 \%$ \\
\hline \multirow{5}{*}{ Outer domain } & summer & $2.1 \%$ & $2.0 \%$ & $95.7 \%$ \\
& winter & $11.2 \%$ & $8.2 \%$ & $100.9 \%$ \\
& mean & $6.7 \%$ & $5.3 \%$ & $97.9 \%$ \\
& yearly & $6.5 \%$ & $4.0 \%$ & $51.0 \%$ \\
\hline
\end{tabular}

year with a slightly higher variation in winter than in summer. For both radiation and wind, the mean daily NIQR is larger than the NIQR of the mean, which demonstrates the temporal dynamic of the spatial patterns.

\subsection{Point results of SWAP}

Two selected locations, P1 and P2 with distinct topographic features are investigated as a special case of topographic variability. P1 is located at the north side of the mountain foot, whereas P2 is located in the south aspect of the mountain peek. The topographic information of the two points are listed in Table 4. Figure 6 shows the common (see Fig. 6a) and specific meteorological inputs at each location obtained at $100 \mathrm{~m}$ scale (see Fig. 6b) at the two selected points. $\mathrm{P} 2$ receives considerably higher radiation and is exposed to stronger wind (see Fig. 6b). Both points are simulated assuming a vegetation cover of natural grass. Figure $6 \mathrm{c}$ 

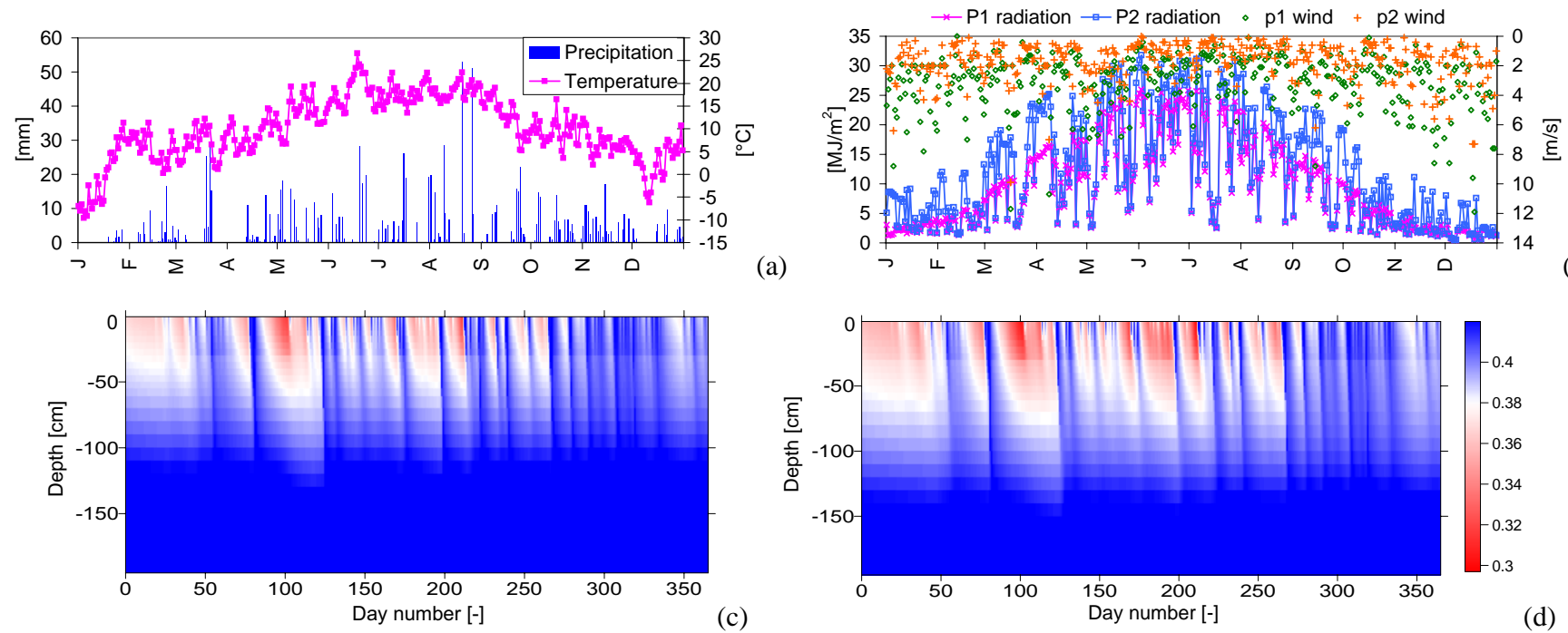

Fig. 6. Meteorological inputs and simulated soil moisture time series at P1 and P2. (a) Precipitation and temperature, (b) radiation and wind, (c) soil moisture profile at P1 and (d) soil moisture profile at P2.

and $6 \mathrm{~d}$ show the soil moisture dynamics of the two points simulated at the spatial resolution of $100 \mathrm{~m}$. The soil moisture dynamics of both points are similar, but P2 is obviously much drier than P1. The driest period is from 24 March to 11 April, during which there is no rainfall in around two weeks.

Table 4 shows the water balance at the two points simulated with the two different soil configurations. At both scales, more water are evaporated/transpired at $\mathrm{P} 2$ associated correspondingly with a higher amount of total runoff generated. There is only a minor difference between ETA and ETP, because southern Germany is a humid region, where ET is energy limited other than water availability limited process. The TA/TP ratio is higher than EA/EP, because water extraction capacity of root zone does not alter much under water stress conditions whereas the soil hydraulic conductivity drops rapidly with decreasing saturation. EA is even more reduced with regard to EP for the more permeable soil configuration which have lower suction heads at the same degree of saturation. However, soil has very limited effects on the total amount of ET and runoff, it alters only the partitioning between evaporation and transpiration, and between surface runoff and subsurface flow. Therefore, in case of more permeable soils, the declination of evaporation is offset by an enhanced transpiration, and meanwhile a stronger infiltration causes consequently dominating drainage through subsurface flow and negligible surface runoff $(1.0 \mathrm{~mm})$.

As shown in the table, at $100 \mathrm{~m}$ resolution, the difference of potential and actual ET at the two points is around $20 \%$, while at $1000 \mathrm{~m}$ resolution the difference is reduced to $14 \%$. The difference of total runoff is $21 \%$ at the fine scale and $15 \%$ at the coarse scale. For less permeable soils, the difference of surface runoff at the two scales are $12 \%$ and $9 \%$ respectively. The results show that the variability in ET and runoff simulated at the two points diminishes with coarser resolution, but still at the coarser scale a significant spatial difference can be observed. Such strong heterogeneity in ET and runoff generation processes may lead to significant hydrological consequences, such as local water balance or erosion patterns, etc.

\subsection{Spatial results of SWAP}

The spatial variabilities are also investigated at the two different scales. Figure $7 \mathrm{a}$ and $\mathrm{b}$ show the statistical distributions of spatial radiation and wind with the probability density function (PDF) for the outer domain, and Fig. 7c-e show the PDFs of the yearly EA, TA, and ETA of the respective numerical experiments. The PDFs (EA, TA, ETA) of Experiment 1 which considers only radiation effects spread much narrower than the corresponding PDFs of other experiments. But the result of Experiment 2 is very close to Experiment 3, which reflects the domination of the wind effects over the radiation effects. The result of Experiment 4 show multiple peaks because of consideration of spatial land use. They are shown separately in Fig. $7 \mathrm{f}$ to avoid the distortion of other experiment results in the figure. To be mentioned, the negative value in Fig. $7 \mathrm{f}$ is a numerical artifacts coming from the kernel smoothing of the distribution curve.

Figure 8 shows the respective PDFs for the inner domain at finer scale. Comparing with the outer domain, radiation has caused a stronger spatial variation of EA, TA and ETA, which is almost comparable to the corresponding variations caused by wind. The enhanced spatial ET variability with finer resolution of spatial radiation has shown that there is a remarkable scale effect in terms of radiation. Although 

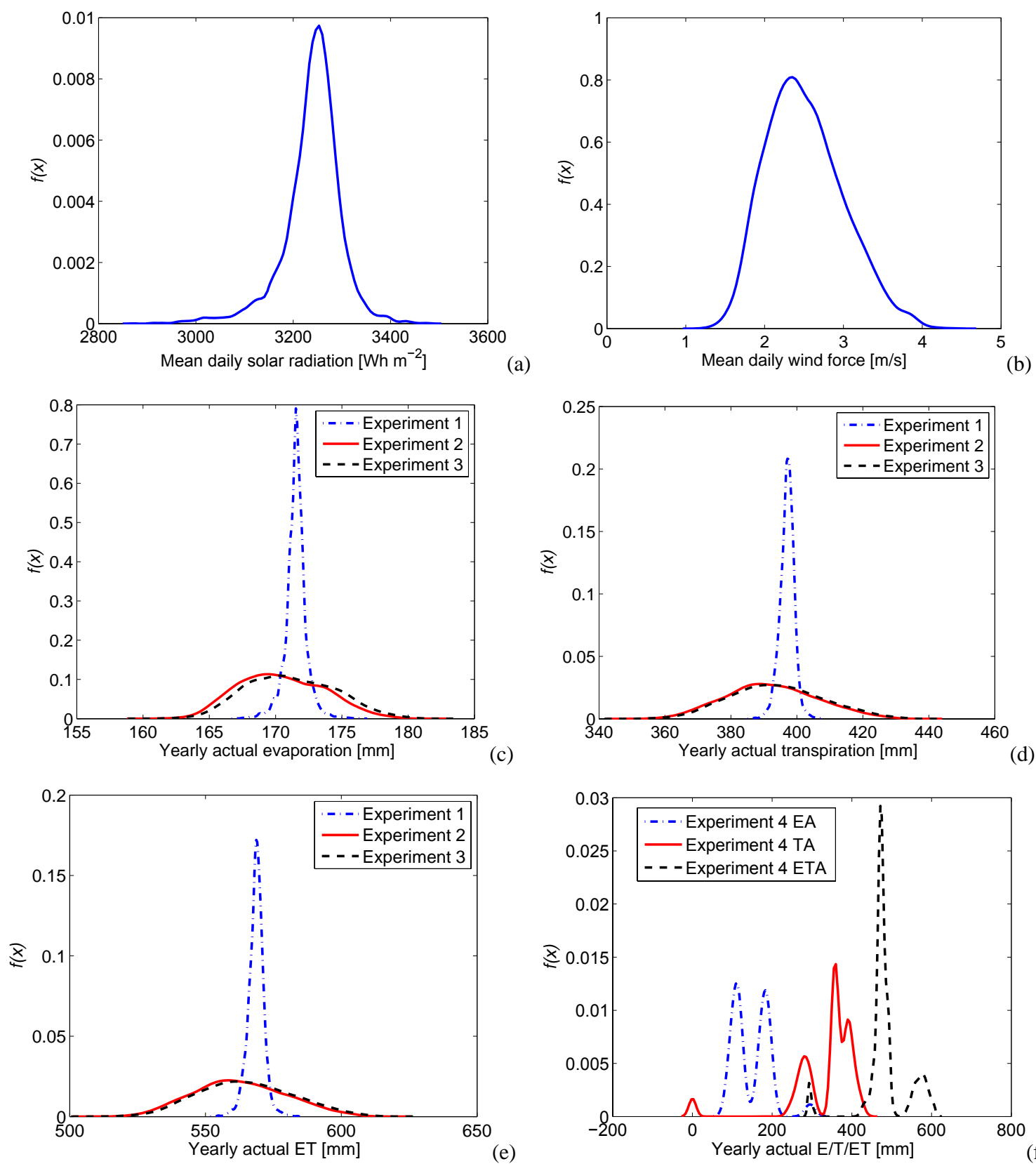

Fig. 7. Spatial variation of meteorological inputs and simulation results with SWAP for the of outer domain - (a) PDF of mean daily solar radiation, (b) PDF of mean daily wind forece, (c) PDF of actual evaporation from Experiment 1, 2 and 3, (d) PDF of actual transpiration of Experiment 1, 2 and 3, (e) PDF of actual ET from Experiment 1, 2 and 3, (f) PDF of actual evaporation, actual transpiration and actual ET of Experiment 4.

radiation aggregation from fine scale to coarse scale helps to maintain the spatial variation inherited from the fine scale, loss of spatial information and thus variation is unavoidable. Similarly to the outer domain, multiple peeks in the PDFs of EA, TA and ETA can be observed for the inner domain (see Fig. 8f). In general, agricultural field has the highest ET and ET is decreasing in the order of grass, deciduous forest, pine forest, to bare soil. Not only the amount of total ET, but also the partitioning between evaporation (E) and transpiration (T) changes with plant type, for example, forest shows higher transpiration because of the strong root uptake capability and higher vegetation cover of soil.

The yearly total actual and potential E/T/ET and their corresponding spatial variation quantified by NIQR is shown in Tables 5 and 6 together the mean daily soil moisture. The variation of ET is much smaller than the corresponding variation of energy input, i.e. wind and solar radiation, because of the nonlinearity of the ET process. For the outer domain 

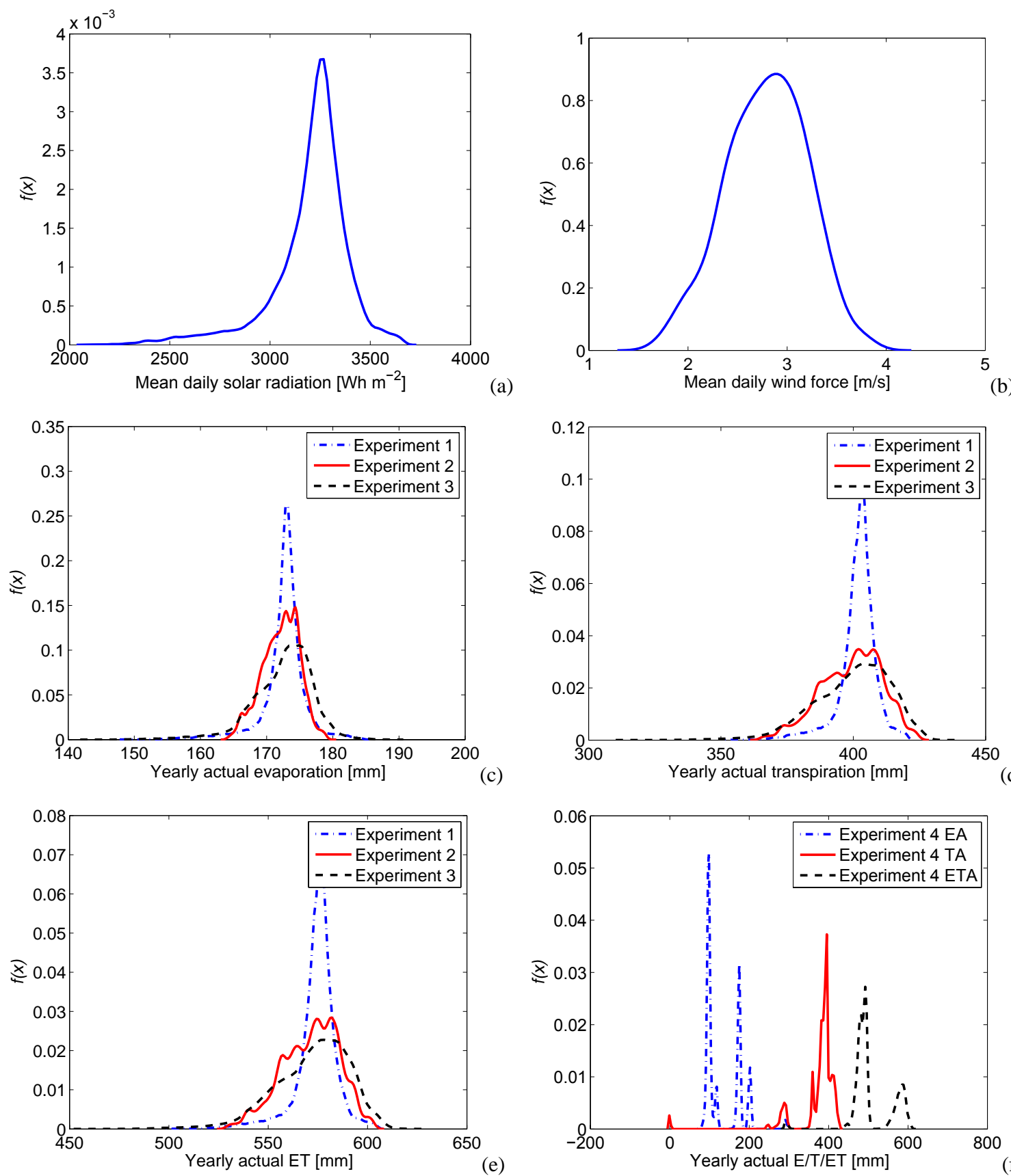

Fig. 8. Spatial variation of meteorological inputs and simulation results with SWAP for the inner domain - (a) PDF of mean daily solar radiation, (b) PDF of mean daily wind forece, (c) PDF of actual evaporation from Experiment 1, 2 and 3, (d) PDF of actual transpiration of Experiment 1, 2 and 3, (e) PDF of actual ET from Experiment 1, 2 and 3, (f) PDF of actual evaporation, actual transpiration and actual ET of Experiment 4.

$1.2 \%$ variation in annual total ETA is resulted from $4.0 \%$ variation of yearly radiation, with $8.0 \%$ ETA variation from $51.0 \%$ variation of yearly mean wind. For the inner domain, $13.0 \%$ variation in radiation and $37.0 \%$ variation in wind are corresponding to $3.5 \%$ and $6.4 \%$ variation in ETA respectively. For both domains, the wind-caused spatial ETA variations are stronger than the ETA variations caused by radiation, and the combination of wind and radiation further increases the spatial variation, but to a very limited amount. However, when the variation of ETA is evaluated relatively to the variation of the corresponding causal factor, the ratio of radiation variation to the ETA variation is much higher 
Table 4. Comparison of point simulation results for P1 and P2 under two different soil configurations.

\begin{tabular}{|c|c|c|c|c|}
\hline & \multicolumn{2}{|c|}{$\mathrm{P} 1$} & \multicolumn{2}{|c|}{$\mathrm{P} 2$} \\
\hline & $100 \mathrm{~m}$ & $1000 \mathrm{~m}$ & $100 \mathrm{~m}$ & $1000 \mathrm{~m}$ \\
\hline elevation [m] & 616 & 608 & 820 & 811 \\
\hline aspect [degree] & 315.0 & 6.92 & 194.5 & 188.8 \\
\hline slope [degree] & 26.98 & 5.74 & 5.97 & 1.46 \\
\hline mean radiation $\left[\mathrm{MJ} \mathrm{m}^{-2}\right]$ & 9.33 & 10.54 & 12.25 & 11.98 \\
\hline mean wind $\left[\mathrm{ms}^{-1}\right]$ & \multicolumn{2}{|c|}{1.73} & \multicolumn{2}{|c|}{3.10} \\
\hline \multicolumn{5}{|c|}{ Acutal soil (Soil A \& B) } \\
\hline Initial water storage $[\mathrm{mm}]$ & 801.5 & 802.1 & 786.0 & 786.7 \\
\hline transpiration $[\mathrm{mm}]$ & $339.1(343.1)$ & $357.1(360.9)$ & $417.1(419.6)$ & $414.1(416.6)$ \\
\hline evaporation [mm] & $154.3(197.4)$ & $161.9(214.7)$ & $177.7(248.8)$ & $176.1(244.9)$ \\
\hline drainage $[\mathrm{mm}]$ & 509.7 & 486.7 & 411.5 & 416.3 \\
\hline runoff $[\mathrm{mm}]$ & 88.0 & 85.9 & 78.7 & 78.9 \\
\hline Final water storage $[\mathrm{mm}]$ & 816.8 & 817.1 & 807.4 & 807.8 \\
\hline \multicolumn{5}{|c|}{ Test soil (Soil C \& D) } \\
\hline Initial water storage $[\mathrm{mm}]$ & 654.2 & 656.1 & 601.2 & 603.6 \\
\hline transpiration $[\mathrm{mm}]$ & $344.3(344.3)$ & 361.9 (361.9) & $421.7(421.7)$ & $418.7(416.6)$ \\
\hline evaporation [mm] & $146.6(196.2)$ & $153.2(213.6)$ & $167.3(246.7)$ & $165.8(244.9)$ \\
\hline drainage $[\mathrm{mm}]$ & 600.9 & 577.5 & 495.8 & 500.0 \\
\hline runoff $[\mathrm{mm}]$ & 0.8 & 0.2 & 0.3 & 0.0 \\
\hline Final water storage $[\mathrm{mm}]$ & 668.2 & 669.8 & 622.6 & 624.6 \\
\hline
\end{tabular}

Note: The values in the parentheses are potential values.

Table 5. Annual results from the numerical experiments with SWAP for the outer domain.

\begin{tabular}{|c|c|c|c|c|c|c|c|c|c|c|c|}
\hline & \multicolumn{7}{|c|}{ Spatial variation $\frac{P_{90}-P_{10}}{\mu_{\mathrm{s}}}$ of yearly total $(\%)$} & \multicolumn{4}{|c|}{ Annual area mean $(\mathrm{mm})$} \\
\hline & EA & EP & $\mathrm{TA}$ & TP & ETA & ETP & $\mathrm{SMC}^{*}$ & EA & EP & TA & TP \\
\hline EX 1 & 1.0 & 2.1 & 1.3 & 1.1 & 1.2 & 1.5 & 2.0 & 172.0 & 236.0 & 398.1 & 401.3 \\
\hline EX 2 & 4.9 & 6.2 & 9.3 & 9.0 & 8.0 & 8.0 & 2.4 & 170.9 & 233.9 & 393.5 & 396.7 \\
\hline EX 3 & 5.0 & 6.8 & 9.4 & 9.0 & 8.1 & 8.2 & 2.4 & 171.6 & 235.7 & 395.0 & 398.3 \\
\hline EX 4 & 62.2 & 113.7 & 39.7 & 33.5 & 24.6 & 34.7 & 4.4 & 150.6 & 228.9 & 336.1 & 359.9 \\
\hline
\end{tabular}

* Mean daily spatial soil moisture variation over the year.

than the ratio between wind and ET. In all cases, the spatial variation of the actual value is smaller than the potential value for evaporation, while transpiration shows in most cases different behaviour, i.e. variation of potential transpiration is smaller than variation of actual transpiration. The reason may come from the threshold effects of root uptake under stress conditions as shown in Fig. 3 which may cause a spatially heterogeneous reduction of TA from TP, whereas the reduction of soil water transfer is more continuous. In this study, the actual E/T/ET at both scales happen to decrease from Experiment 1 to Experiment 3, which is related to the specific topography of the study area and should not be considered as general. But the remarkable decrease of E/T/ET when actual land use is considered is logical, because grass is one of the land uses with strongest ET.

The inner domain shows a stronger variation than the outer domain for Experiment 1, but when the effect of spatial wind is considered, the strong wind-induced ET variation will dominating the increase of ET variation caused by radiation at finer resolution, as shown by comparison of Experiment 2 for both domains. The inner domain also shows a higher yearly area mean ET, because it is lying on a mountainous region and is exposed in average to stronger wind and radiation inputs. In general for both domains, the spatial variation of the daily mean SMC is very weak, even for assessment based on the yearly total or mean does not take into account 
Table 6. Annual results from the numerical experiments with SWAP for the inner domain.

\begin{tabular}{|c|c|c|c|c|c|c|c|c|c|c|c|}
\hline & \multicolumn{7}{|c|}{ Spatial variation $\frac{P_{90}-P_{10}}{\mu_{\mathrm{s}}}(\%)$} & \multicolumn{4}{|c|}{ Annual area mean $(\mathrm{mm})$} \\
\hline & EA & EP & TA & $\mathrm{TP}$ & ETA & ETP & $\mathrm{SMC}^{*}$ & EA & EP & TA & $\mathrm{TP}$ \\
\hline EX 1 & 3.6 & 7.0 & 3.5 & 3.4 & 3.5 & 4.7 & 1.8 & 173.1 & 237.4 & 402.8 & 405.8 \\
\hline EX 2 & 4.1 & 5.1 & 7.4 & 7.1 & 6.4 & 6.4 & 2.0 & 172.6 & 236.7 & 400.4 & 403.4 \\
\hline EX 3 & 6.1 & 9.3 & 9.1 & 8.7 & 8.1 & 8.8 & 2.2 & 172.9 & 237.3 & 400.7 & 403.7 \\
\hline EX 4 & 77.5 & 148.2 & 31.7 & 28.9 & 22.9 & 33.4 & 4.0 & 134.3 & 180.7 & 374.7 & 378.0 \\
\hline
\end{tabular}

* Mean daily spatial soil moisture variation over the year.

Table 7. Seasonal results of the numerical experiments for the outer domain.

\begin{tabular}{llrrrrrrr}
\hline & & \multicolumn{6}{c}{ Mean/maximum of daily spatial variation $\frac{P_{90}-P_{10}}{\mu_{\mathrm{s}}}(\%)$} \\
\cline { 3 - 9 } & & EA & EP & TA & TP & ETA & ETP & SMC \\
\hline \multirow{2}{*}{ EX 1 } & winter & 15.5 & 15.6 & 2.6 & 2.0 & 3.9 & 3.7 & 4.6 \\
& summer & 0.8 & 1.5 & 1.9 & 1.0 & 1.5 & 1.2 & 1.7 \\
& mean & 5.6 & 6.2 & 4.1 & 2.8 & 2.0 & 3.4 & 2.0 \\
\hline \multirow{2}{*}{ EX 2 } & winter & 51.9 & 52.2 & 57.0 & 56.7 & 54.9 & 54.7 & 5.0 \\
& summer & 5.4 & 7.9 & 12.4 & 11.7 & 8.8 & 8.5 & 2.1 \\
& mean & 32.4 & 34.2 & 40.5 & 40.0 & 37.1 & 36.9 & 2.4 \\
\hline \multirow{2}{*}{ EX 3 } & winter & 58.6 & 58.9 & 57.2 & 56.9 & 55.2 & 55.0 & 5.0 \\
& summer & 7.8 & 8.4 & 12.6 & 11.9 & 9.0 & 8.7 & 2.2 \\
& mean & 34.6 & 36.7 & 40.8 & 40.0 & 37.5 & 37.4 & 2.4 \\
\hline \multirow{2}{*}{ EX 4 } & winter & 179.5 & 200.0 & 186.6 & 237.0 & 133.2 & 141.0 & 6.19 \\
& summer & 101.4 & 136.9 & 107.0 & 48.6 & 74.0 & 64.6 & 4.4 \\
& mean & 135.0 & 165.5 & 164.2 & 174.3 & 99.6 & 95.8 & 4.8 \\
\hline
\end{tabular}

the varying interaction of radiation and wind over time. To have an insight of the spatial variation over time, the daily mean spatial variations from the outer domain are calculated for winter (from November to Feburary) and summer (from May to August) respectively in Table 7.

It is shown that for all 4 experiments, the variation of E/T/ET/SMC are stronger in winter than in summer. The seasonal difference in ET of Experiment 1 is mainly caused by radiation with little effect from the wind, as the resulting variation of ET is almost proportional to the variation of radiation for the two different seasons. However, in winter plant transpiration (NIQR $=2.6$ and 2.0) is much less affected by radiation than soil evaporation (NIQR $=15.5$ and 15.6), and the opposite holds for summer. This may have a strong implication for the spring flood in some regions. Experiment 2 shows that the effect of wind is conditioned differently on radiation for the two different seasons. In winter, wind is the major driving force for ET, the variation of wind is almost fully translated to the variation of the resulting ET. But in summer, radiation is dominating wind for the ET process, therefore strong spatial wind variation leads to only very limited ET variation. The seasonal results of Experiment 3 is mot much different from Experiment 2, which shows that the variation caused by accounting for the spatial radiation in addition to spatial wind is very limited. The heterogeneity of land use has significantly increased the ET variation for summer comparing to for winter. The spatial variation of SMC also shows some seasonal change, but not as dramatic as ET.

The correlation of ETA from the four experiments with the three primary topographic parameters are listed in $\mathrm{Ta}-$ ble 8 . Similarly to Table 2, aspect and slope are transformed for radiation. For Experiment 1, comparing to radiation itself, spatial ETA driven by it shows a reduced correlation to $\cos \gamma(\bar{\rho}=0.25)$ and enhanced correlation to elevation $(\bar{\rho}=0.25)$ with much larger standard deviation, which is probably resulted from the interaction of radiation with wind and the process nonlinearity. The correlation of windinduced ETA of Experiment 2 to elevation is also reduced, with a mean correlation coefficient of 0.24 and a standard deviation of 0.29 comparing to the correlation between wind and elevation. However, from the perspective of yearly mean ETA, the correlation to both aspect and elevation is still very 
Table 8. Correlation between ET patterns and topographic parameters for the outer domain ( $\bar{\rho}$ is the yearly mean of daily correlation coefficients between daily ET pattern and topographic parameters, and $\sigma$ is the corresponding standard deviation. $\tilde{\rho}$ is the correlation of mean daily ET pattern with topographic parameters.)

\begin{tabular}{|c|c|c|c|c|c|c|c|c|c|c|c|c|}
\hline & \multicolumn{3}{|c|}{ EX 1} & \multicolumn{3}{|c|}{ EX 2} & \multicolumn{3}{|c|}{ EX 3} & \multicolumn{3}{|c|}{ EX 4} \\
\hline & $\bar{\rho}$ & $\sigma$ & $\tilde{\rho}$ & $\bar{\rho}$ & $\sigma$ & $\tilde{\rho}$ & $\bar{\rho}$ & $\sigma$ & $\tilde{\rho}$ & $\bar{\rho}$ & $\sigma$ & $\tilde{\rho}$ \\
\hline$\gamma$ & 0.25 & 0.36 & 0.62 & -0.02 & 0.13 & -0.07 & 0.04 & 0.21 & 0.03 & 0.01 & 0.05 & 0.03 \\
\hline$\beta$ & -0.14 & 0.25 & -0.20 & 0.00 & 0.10 & 0.01 & -0.02 & 0.13 & -0.02 & -0.04 & 0.21 & 0.00 \\
\hline$\delta$ & 0.25 & 0.37 & 0.43 & 0.24 & 0.29 & 0.56 & 0.26 & 0.28 & 0.58 & 0.10 & 0.23 & 0.33 \\
\hline
\end{tabular}

strong with $\tilde{\rho}$ being 0.62 for aspect and 0.56 for elevation respectively. When the spatial heterogeneity of both radiation and wind are considered, the resulting ETA shows correlation only to elevation, which seems to confirm again the domination of wind over radiation. As shown in the results of Experiment 4, the dependence of ETA on elevation can still be detected ( $\bar{\rho}=0.10)$, even if spatial land use is considered. Because of the assumption of linear groundwater table in this study, SMC will show predominantly correlation to elevation, which is trivial to be listed in the table.

To have a close look at the varying ET pattern over time, Fig. 9 shows the spatial variation of actual ET over the year for the outer domain resulted from Experiment 3 as an example. In the winter time, although the amount of ET is relatively small, the variation in terms of NIQR can be as high as $180 \%$, which may have an implication on spring and winter flood.

\section{Discussion}

In this paper, numerical experiments with the SWAP model have been applied to a mountainous region at two different scales to simulate ET and SMC and examine the effects of spatial radiation and wind induced by topography on them. The study applies physically-based models to simulate spatial radiation and wind, and analyzes the resulting spatial variation of ET/SMC. Simulations with spatial vegetation information obtained from MODIS LAI are also performed to check the effect of land use on ET/SMC. The result shows that both radiation and wind vary strongly over spatial, with radiation being aspect dependent and wind being elevation dependent. The spatial variation of radiation is much higher in winter than in summer, while the spatial variation of wind is relatively constant over the year. Investigation at locations with distinct topographic features have shown that the difference in incoming radiation and wind will lead to strong difference in ET/SMC. The spatial difference in ET is offset by the amount of runoff generated, which may have an implication in flood generation. Different soil conditions will change the partitioning between evaporation and transpiration and, the partitioning between surface runoff and subsurface flow,

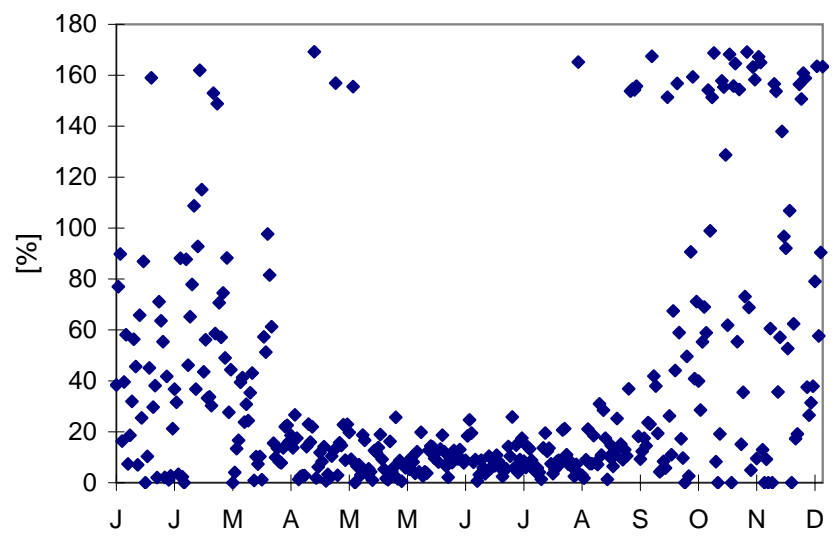

Fig. 9. Daily spatial variation of ETA from Experiment 3 for the outer domain.

but has very limited impact on total amount of ET and runoff. Spatial investigation with 4 numerical experiments shows that the spatial variation of the both driving factors will further propagate to ET/SMC, which show significant seasonal difference in their spatial variation, i.e. higher in winter and lower in summer. This may have an impact on the forecast of spring flood. Because in the study region ET is an energy limited rather than water availability limited process, the spatial variability of radiation and wind has a much more pronounced effect on the spatial variation of ET than SMC. Although wind is in general the dominating factor for ET processes, radiation causes a pronounced spatial variation in evaporation, which is remarkably larger than the original variation of spatial radiation. Under the aerodynamic process dominating conditions in winter, the spatial variation of wind can be fully reflected in the spatial variation of ET, which is otherwise very limited in summer. ET shows a radiation dependent scale effect, but the increase of ET variation at fine scale will be dominated by wind if spatial wind is active considered. Correlation analysis shows that comparing to the respective spatial driving force, i.e. radiation and wind, the resulting ETA shows weaker but still significant correlation with the corresponding topographic parameter, especially when annual mean is considered. ETA shows a 
predominantly dependence on elevation under the interaction of radiation and wind, and such dependence can still be detected, even if spatial land use is considered.

In this study, the SWAP model is applied with radiation and wind data mapped from global data and physically-based model, which demand very few observation data. Because the lack of groundwater data, a linear groundwater table is assumed for the numerical experiments which may be improved by coupling the SWAP model with a groundwater model to update the groundwater level at each time step. However, the methodology applied in this research can still serves as a general approach for ETA simulation for datasparse regions.

This study has confirmed the effects of topographic induced spatial radiation and wind on ET, and this information may be utilized to improve hydrological concepts in ET/SMC modeling. Moore et al. (1993) derived a dimensionless evaporation scaling ratio based on spatial radiation differences. Vertessy et al. (1990) developed a radiation weighted wetness index, which is a combination of potential solar radiation index (the ratio of the potential solar radiation on a sloping surface to that on a horizontal surface) and wetness index. As demonstrated in this study wind is in some cases dominating radiation, therefore the inclusion of wind effect into the wetness index following a statistical approach should be considered in the future.

Acknowledgements. The authors thank the International Postgraduate Studies in Water Technologies (IPSWaT) of the German Federal Ministry of Education and Research (BMBF) and the International Doctoral Program Environment Water (ENWAT) at the University of Stuttgart for support of the research.

Edited by: I. Neuweiler

\section{References}

Andersen, J., Sandholt, I., Jensen, K. H., Refsgaard, J. C., and Gupta, H.: Perspectives in using a remotely sensed dryness index in distributed hydrological models at the river-basin scale, Hydrol. Process., 2987, 2973-2987, doi:10.1002/hyp.1080, 2002.

Baklanov, A., Fay, B., Kaminski, J., and Sokhi, R.: Overview of Existing Integrated (off-line and on-line) Mesoscale Meteorological and Chemical Transport Modelling Systems in Europe, WMO publications, Tech. rep., COST (Enhancing Mesoscale Meteorological Modelling Capacities for Air Pollution and Dispersion Applications) and GURME (GAW Urban Research Meteorology and Environment Project), 2008.

Bastiaanssen, W. G. M., Menenti, M., Feddes, R. A., and Holtslag, A. A. M.: A remote sensing surface energy balance algorithm for land (SEBAL), 1. Formulation, J. Hydrol., 212-213, 198-212, doi:10.1016/S0022-1694(98)00253-4, 1998.

Beven, K. J. and Kirkby, M. J.: A physically based, variable contributing area model of basin hydrology, Hydrolog. Sci. Bull., 24, 43-69, 1979.
Beven, K. J., Lamb, R., Quinn, P., Romanowicz, R., and Freer, J.: TOPMODEL, in: Computer models of watershed hydrology, edited by: Singh, V. P., Highlands Ranch, Colo., Water Resources Publications, 1995.

Black, T. A., Gardner, W. R., and Thurtell, G. W.: The prediction of evaporation, drainage and soil water storage for a bare soil, Soil Sci. Soc. Am., 33, 655-660, 1969.

Boesten, J. and Stroosnijder, L.: Simple model for daily evaporation from fallow tilled soil under spring conditions in a temperate climate, Neth. J. Agr. Sci., 34, 75-90, 1986.

Bois, B., Pieri, P., Leeuwen, C. V., Wald, L., Huard, F., Gaudillere, J.-P., and Saur, E.: Using remotely sensed solar radiation data for reference evapotranspiration estimation at a daily time step, Agr. Forest Meteorol., 148, 619-630, doi:10.1016/j.agrformet.2007.11.005, 2008.

Bresnahan, P. A. and Miller, D. R.: Choice of data scale: predicting resolution error in a regional evapotranspiration model, Agr. Forest Meteorol., 84, 97-113, 1997.

Cano, D., Monget, J. M., Albuisson, M., Regas, H. G., and Wald, L.: A method for the determination of the global solar radiation from meteorological satellite data, Sol. Energy, 37, 31-39, 1986.

Carlson, T. N., Capehart, W. J., and Gillies, R. R.: A new look at the simplified method for remote sensing of daily evapotranspiration, Remote Sens. Environ., 54, 161-167, doi:10.1016/00344257(95)00139-R, 1995.

Cassardo, C., Balsamo, G. P., Cacciamani, C., Cesari, D., Paccagnella, T., and Pelosini, R.: Impact of soil surface moisture initialization on rainfall in a limited area model: a case study of the 1995 South Ticino flash flood, Hydrol. Process., 16, 13011317, 2002.

Cleugh, H. A., Leuning, R., Mu, Q., and Running, S. W.: Regional evaporation estimates from flux tower and MODIS satellite data, Remote Sens. Environ., 106, 285-304, 2007.

Crave, A.: The influence of topography on time and space distribution of soil surface water content, Hydrol. Process., 11, 203-210, 1997.

Dingman, S. L.: Physical Hydrology, Prentice-Hall, Inc., 2nd Edn., 2002.

El Maayar, M. and Chen, J. M.: Spatial scaling of evapotranspiration as affected by heterogeneities in vegetation, topography, and soil texture, Remote Sens. Environ., 102, 33-51, doi:10.1016/j.rse.2006.01.017, 2006.

FAO: Expert consultation on revision of FAO methodologies for crop water requirements, ANNEX V: FAO Penman-Monteith Formula, Tech. rep., FAO, Rome, Italy, 1990.

Florinsky, I., Eilers, R., Manning, G., and Fuller, L.: Prediction of soil properties by digital terrain modelling, Environ. Model. Softw., 17, 295-311, doi:10.1016/S1364-8152(01)00067-6, 2002.

Frank, H. and Landberg, L.: Modelling waving crops in a wind tunnel, Bound.-Lay. Meteorol., 85, 359-377, 1997.

Hofierka, J. and Suri, M.: The solar radiation model for Open source GIS: implementation and application, in: Proceddings of the Open source GIS - GRASS users conference 2002, Trento, Italy, 2002.

Jenny, H.: Factors of Soil Formation: A System of Quantitative Pedology, McGraw Hill Book Company, New York, NY, USA, 1941. 
Jensen, M., Burman, R., and Allen, R.: Evapotranspiration and irrigation water requirements, ASCE manuals and reports on engineering practice 70, ASCE, New York, 1990.

Kalnay, E., Kanamitsu, M., Kistler, R., Collins, W., Deaven, D., Gandin, L., Iredell, M., Saha, S., White, G., Woollen, J., Zhu, Y., Leetmaa, A., Reynolds, R., Chelliah, M., Ebisuzaki, W., Higgins, W., Janowiak, J., Mo, K. C., Ropelewski, C., Wang, J., Jenne, R., and Joseph, D.: The NCEP/NCAR 40-year reanalysis project, B. Am. Meteorol. Soc., 77, 437-471, doi:10.1175/15200477(1996)077<0437:TNYRP>2.0.CO;2, 1996.

Kasten, F.: Parametriserung der Globalstrahlung durch Bedeckungsgrad und Trbungsfaktor, Ann. Meteorol., 20, 49-50, 1983.

Lenz, C. J., Müller, F., and Schlünzen, K.: The sensitivity of mesoscale chemistry transport model results to boundary values, Environ. Monitor. Assess., 65, 287-295, 2000.

Liu, M., Bárdossy, A., Li, J., and Jiang, Y.: GIS-based modeling of topography-induced solar radiation variability in complex terrain for data sparse region, Int. J. Geogr. Inf. Sci., in press, 2011.

Mikhail Sofiev, A. I. and Miranda, R. S.: Joint report of COST Action 728 and GURME: Review of the capacities of meteorological and chemistry-transport models for describing and preidicting air pollution episodes, WMO publications, Tech. rep., COST - Enhancing Mesoscale Meteorological Modelling Capacities for Air Pollution and Dispersion Applications - and GURME - GAW Urban Research Meteorology and Environment Project, 2009.

Mohanty, B. P. and Skaggs, T. H.: Spatio-temporal evolution and time-stable characteristics of soil moisture within remote sensing footprints with varying soil, slope, and vegetation, Adv. Water Resour., 24, 1051-1067, doi:10.1016/S0309-1708(01)00034-3, 2001.

Moore, I. D., Gallant, J. C., and Guerra, L.: Modelling the spatial variability of hydrological process using GIS, in: HydroGIS 93: Application of Geographic Information System in Hydrology and Water Resources, Proceedings of Viena Conference, IAHS Publication, 1993.

Mu, Q., Heinsch, F. A., Zhao, M., and Running, S. W.: Development of a global evapotranspiration algorithm based on MODIS and global meteorology data, Remote Sens. Environ., 111, 519536, doi:10.1016/j.rse.2007.04.015, 2007.

Norbiato, D., Borga, M., Esposti, S. D., Gaume, E., and Anquetin, S.: Flash flood warning based on rainfall thresholds and soil moisture conditions: An assessment for gauged and ungauged basins, J. Hydrol., 362, 274-290, 2008.

Odeh, I. O. A., McBratney, A. B., and Chittleborough, D. J.: Spatial prediction of soil properties from landform attributes derived from a digital elevation model, Geoderma, 63, 197-214, 1994.

Ostendorf, B. and Reynolds, J. F.: A model of arctic tundra vegetation derived from topographic gradients, Landscape Ecology, 187-201, 1998

Penman, H. L.: Natural evaporation from open water, bare soil and grass, P. Roy. Soc. A, 193, 120-146, 1948.

Price, J.: Using Spatial Context in Satellite Data to Infer Regional Scale Evapotranspiration, IEEE T. Geosci. Remote, 28, 940-948, 1990.

Quinn, P. F. and Beven, K. J.: Spatial and temporal predictions of soil moisture dynacmics, runoff, variable source areas and evapotranspiration for plynlimon, Mid-Wales, Source, 7, 425-448, 1993.
Reed, D. N., Anderson, T. M., Dempewolf, J., Metzger, K., and Serneels, S.: The spatial distribution of vegetation types in the Serengeti ecosystem: the influence of rainfall and topographic relief on vegetation patch characteristics, J. Biogeogr., 36, 770782, doi:10.1111/j.1365-2699.2008.02017.x, 2009.

Rigollier, C., Lefèvre, M., and Wald, L.: The method Heliosat-2 for deriving shortwave solar radiation from satellite images, Sol. Energy, 77, 159-169, 2004.

Schlünzen, K. H., Bigalke, K., Lüpkes, C., and Panskus, H.: Documentation of the mesoscale transport- and fluid model METRAS PC as part of model system METRAS+, Tech. rep., Meteorologisches Institut, Universitt Hamburg, mETRAS Technical Rep. 11, 2001.

Schröder, B.: Pattern, process, and function in landscape ecology and catchment hydrology - how can quantitative landscape ecology support predictions in ungauged basins?, Hydrol. Earth Syst. Sci., 10, 967-979, doi:10.5194/hess-10-967-2006, 2006.

Schueler, S. and Schlünzen, K. H.: Modeling of oak pollen dispersal on the landscape level with a mesoscale atmospheric model, Environ. Model. Assess., 11-3, 179-194, 2006.

Su, Z.: The Surface Energy Balance System (SEBS) for estimation of turbulent heat fluxes, Hydrol. Earth Syst. Sci., 6, 85-100, doi:10.5194/hess-6-85-2002, 2002.

Thornthwaite, C. W. and Mather, J. R.: The Water Balance, Publ. Climatol., 8, 188, 1955.

Thornton, P. E., Running, S. W., and White, M. A.: Generating surfaces of daily meteorological variables over large regions of complex terrain, J. Hydrol., 190, 214-251, doi:10.1016/S00221694(96)03128-9, 1997.

van Dam, J., Huygen, J., Wesseling, J. R. A. F., Kabat, P., van Walsum, P., Groenendijk, P., and van Diepen, C.: Theory of SWAP version 2.0, Tech. rep., Department of Water Resources, Wageningen Agricultural University, Wageningen, The Netherlands, 1997.

Guideline VDI 3783: Environmental Meteorology, Association of German Engineers, 2005.

Verstraeten, W. W., Veroustraete, F., and Feyen, J.: Assessment of Evapotranspiration and Soil Moisture Content Across Different Scales of Observation, Sensors, 8, 70-117, 2008.

Vertessy, R., Wilson, C., Silburn, D., Connolly, R., and Ciesiolka, C.: Predicting erosion hazard areas using digital terrain analysis, AHS AISH Publ., 192, 298-308, 1990.

Wang, K., Wang, P., Li, Z., Cribb, M., and Sparrow, M.: A simple method to estimate actual evapotranspiration from a combination of net radiation, vegetation index , and temperature, J. Geophys. Res., 112, 1-14, doi:10.1029/2006JD008351, 2007.

Western, A. W., Grayson, R. B., Blöschl, G., and Willgoose, G. R.: Observed spatial organization of soil moisture indices, Water Resour., 35, 797-810, 1999.

Western, A. W., Grayson, R. B., and Blöschl, G.: Scaling of Soil Moisture: A Hydrologic Perspective, Ann. Rev. Earth Planet. Sc., 30, 149-180, 2002.

$\mathrm{Wu}, \mathrm{Z}$. and Schlünzen, K. H.: Numerical study on the local wind structures forced by the complex terrain of Qingdao area, Acta Meteorol. Sinica, 6, 355-366, 1992.

$\mathrm{Xu}$, C. Y. and Singh, V. P.: Evaluation and generalization of radiation-based methods for calculating evaporation, Hydrol. Process., 14, 339-349, 2000. 
Yang, W., Tan, B., Huang, D., Rautiainen, M., Shabanov, N. V., Wang, Y., Privette, J. L., Huemmrich, K. F., Fensholt, R., Sandholt, I., Weiss, M., Ahl, D. E., Gower, S. T., Nemani, R. R., Knyazikhin, Y., and Myneni, R. B.: MODIS Leaf Area Index Products: From Validation to Algorithm Improvement, IEEE T. Geosci. Remote, 44, 1885-1898, 2006.
Yeh, P. J.-F. and Eltahir, E. A. B.: Stochastic analysis of the relationship between topography and the spatial distribution of soil moisture, Water Resour. Res., 34, 1251, doi:10.1029/98WR00093, 1998. 